\title{
Avaliação e natureza administrativa das instituições de ensino superior *
}

Magno Federici Gomes**

\section{Resumo}

Objetiva-se, com o presente trabalho, o estudo das normas referentes à heterogeneidade das Instituições de Ensino Superior (IES), ou seja, dos seus diversos níveis de abrangência e especialização, existentes na Constituição da República brasileira de 1988 (BRASIL, 1988), no ordenamento infraconstitucional e em atos administrativos normativos, já que o ensino superior foi reconfigurado várias vezes, dentro do sistema educacional brasileiro. É necessário apresentar classificações adequadas a um ensino superior tão diverso e heterogêneo quanto o brasileiro, bem como discutir a concepção de universidade. Ademais, devem ser analisados a natureza, o regime jurídico das IES, a partir dos setores público e privado, e seus niveis de abrangência ou especialização. Este artigo é preponderantemente teórico-documental, sob uma perspectiva dogmática, empregada como forma de análise dos resultados. Como conclusão, verificou-se a inconstitucionalidade parcial dos Decretos n's 5.773 (BRASIL, 2006b) e 5.786 (BRASIL, 2006c), expedidos pela Presidência da República brasileira, no tópico relativo aos diversos níveis de abrangência ou especialização das IES, especialmente nas denominações de centros universitários e faculdades. A discriminação formulada pelos atos administrativos normativos não se limita a organizar as IES do sistema federal de ensino, posto que cria formas de organização institucional, sem disposição legal anterior e em sentido oposto ao do art. 45 Lei no 9.394 (BRASIL, 1996). Finalmente, o Projeto de Lei de Reforma Universitária, em trâmite no Congresso Nacional brasileiro, apresenta, em seu texto, elementos que possibilitam regularizar as inconstitucionalidades apontadas por este estudo.

Palavras-chave: Direito constitucional. Direito administrativo. Heterogeneidade das instituições de ensino superior. Níveis de especialização. Inconstitucionalidade parcial de atos administrativos normativos presidenciais.

\footnotetext{
0 presente artigo é resultado da investigação pós-doutoral em Direito Público, na Universidade Nova de Lisboa, Portugal, fomentada pela CAPES (Coordenação de Aperfeiçoamento de Pessoal de Nivel Superior, do Ministério de Educação) e pela Pontifícia Universidade Católica de Minas Gerais (PUC-Minas).

* Pós-doutor em Direito Público e Educação, Universidade Nova de Lisboa, PT. Professor Adjunto da PUC-Minas. E-mail: federici@pucminas.br
} 


\section{Evaluation And Administrative Nature Of The Institutions of Higher Education Abstract}

It is desired, with the present work, the study of the norms relative to the heterogeneity of the Institutions of Higher Education (IES), that is, of its diverse levels of specialization, existing in the Constitution of the Brazilian Republic of 1988 (CR) 88), under the constitutional ordering and normative administrative acts, since superior education was reshaped several times, in the Brazilian educational system. It is necessary to present classifications adapted to such a diverse and heterogeneous higher education system of the Brazilian, as well as to discuss the conception of university. The nature and the legal regime of the IES must be analyzed, from the public and private sectors, and their levels of specialization. This one is a preponderantly theoretical-documentary work, in a dogmatic perspective, employed as a form of analysis of the results. As conclusion, the partial unconstitutionality of Decrees $n^{\circ}$ 5.773/06 and 5.786/06, sent by the Presidency of the Brazilian Republic, has been verified in the topic referring to the diverse levels of specialization of the IES, especially in the denominations of university centers and faculties. The discrimination formulated by the normative administrative acts is not limited to organize the IES of the federal system of education, since it creates forms of institutional organization, without previous legal disposition and in sense opposed to the article 45, of the Law $n^{\circ}$ 9.394/96 (LDB). Finally, the Project of Law of the University Reformation, proceeding in the Brazilian National Congress, presents, in its text, elements that make it possible to regularize unconstitutionalities indicated in this study. Keyword: Constitutional Law; Administrative Law; Heterogeneity of the Institutions of Higher Education; Levels of Specialization; Partial Unconstitutionality of Presidential Normative Administrative Acts.

\section{Evaluación y naturaleza administrativa de las instituciones de enseñanza superior Resumen}

Se desea, con el presente trabajo, el estudio de las normas relativas a la heterogeneidad de las Instituciones de Enseñanza Superior (IES), o sea, sus diversos niveles de especialización, existentes en la Constitución de la República brasileña de 1988 (BRASIL, 1988), en el ordenamiento infraconstitucional y en actos administrativos normativos, ya que la enseñanza superior fue reconfigurada varias veces en el sistema educacional brasileño. Es necesario presentar clasificaciones adecuadas a una enseñanza superior tan plural y heterogénea como la brasileña, además de discutir la concepción de universidad. Deben analizarse la naturaleza, el régimen jurídico de las IES, desde los sectores público y privado, y sus niveles de 
especialización. Se trata de un trabajo preponderantemente teórico-documental, en una perspectiva dogmática, empleada como forma de análisis de los resultados. Como conclusión, se ha verificado la inconstitucionalidad parcial de los Decretos $n^{\circ}$ 5.773 (BRASIL, 2006) y 5.786 (BRASIL, 2006), expedidos por la Presidencia de la República brasileña, en el tópico referente a los diversos niveles de especialización de las IES, especialmente en las denominaciones de centros universitarios y facultades. La discriminación formulada por los actos administrativos normativos no se limita a organizar las IES del sistema federal de enseñanza, puesto que crea formas de organización institucional, sin disposición legal anterior y en sentido opuesto al del artículo 45 Ley no 9.394 (BRASIL, 1996). Finalmente, el Proyecto de Ley de Reforma Universitaria, en trámite en el Congreso Nacional brasileño, presenta, en su texto, elementos que posibilitan regularizar las inconstitucionalidades indicadas en este estudio.

Palabras-clave: Derecho Constitucional. Derecho Administrativo. Heterogeneidad de las Instituciones de Enseñanza Superior. Niveles de Especialización. Inconstitucionalidad Parcial de Actos Administrativos Normativos Presidenciales.

\section{Introdução}

Objetiva-se, com o presente trabalho, o estudo das normas referentes à heterogeneidade das Instituições de Ensino Superior (IES), ou seja, dos seus diversos niveis de abrangência e especialização, existentes na Constituição da República brasileira de 1988 (CR/88) (BRASIL, 1996), no ordenamento infraconstitucional e em atos administrativos normativos, já que o ensino superior foi reconfigurado diversas vezes, dentro do sistema educacional brasileiro.

Com isso, coloca-se em relevo "a instalação de uma tipologia variada de estabelecimentos com características institucionais e práticas acadêmicas bastante diferenciadas" (SOUSA, 2003, p. 12). A referida situação adiciona elementos à relação entre os setores público e privado. Pode-se basear:

[...] em contextos sociais diversos e particularizados. 0 ensino superior brasileiro possui vários cenários que expressam uma pluralidade, tanto do ponto de vista da natureza quanto da dependência administrativa das instituições que o compõem. Tal realidade demanda estudos que tratem esse grau de ensino em sua heterogeneidade, visando questionar o discurso de sua suposta homogeneidade, pretensamente ideologizado. Em um contexto no qual há diferenças de interesses, demandas e organizações internas, 0 discurso da "universidade brasileira" é, portanto, questionável (SOUSA, 2003, p. 12). 
Em tal conjuntura, a expressão universidade brasileira deve ser empregada com cuidado, pois serve "para designar centros de ensino e produção original de conhecimentos, mas também para se referir à totalidade de um complexo sistema" (SOUSA, 2003, p. 12). Em sentido equivalente, comenta-se que, no Brasil, "o ensino superior não esteve tradicionalmente organizado com base na universidade" (RIBEIRO, 2002, p. 17), tendo sido "marcado pelo crescimento do número de escolas isoladas" (RIBEIRO, 2002, p. 19)'. Assim:

[...] que, mais do que um possível equívoco de construção de linguagem, estamos diante da perspectiva, no mínimo questionável, de enfocar a estruturação de um campo educacional onde os estabelecimentos universitários constituem, no estado atual, a exceção (MARTINS, 1997, p. 160).

Trigueiro (2000) e Sousa (2003) continuam demonstrando que considerar uma parte como o todo produz travas à assimilação das frequentes alterações nas IES, em processo de crescimento e expansão. Ademais, tal fato omite a diversa realidade de IES com vocações e situações geográficas completamente distintas. Portanto, a evolução do ensino superior brasileiro é campo acadêmico complexo, rodeado por uma grande heterogeneidade de instituições, cada qual dotada de peculiaridades e características próprias, tanto nas redes pública quanto privada. Nesse sentido:

[...] a observação mais óbvia que se pode fazer sobre o uni-
verso das IES particulares é a de sua profunda heterogenei-
dade, sobretudo, como ficou demonstrado, no segmento
das IES isoladas. Sob a vala comum dessa denominação, en-
tram Instituições de natureza totalmente distintas, assim como
diferentes no porte, tipo e objetivos. As generalizações neste
universo, portanto, tornam-se perigosas, dificeis e desacon-
selháveis e, consequentemente, as imagens formadas são
frequentemente distorcidas dependendo do prisma com que
são vistas as IES (TRAMONTIN; BRAGA, 1984, p. 38) ${ }^{2}$.

Dessa forma, é necessário apresentar classificações adequadas a um ensino superior tão diverso e heterogêneo quanto o brasileiro, recorrendo-se, em parte, aos ensinamentos de Sampaio (2000), Minto (2006) e Muriel (2006), com tal finalidade. Entre as inúmeras distinções constantes na educação superior do Brasil, quando se tem em vista as categorias do público e do privado, uma instituição pode diferenciar-se de outra em vários aspectos formais. Quanto à natureza institucional ou administrativa, as IES podem classificar-se como universidades, centros universitários, faculdades integradas ou estabelecimentos isolados. Quanto à sua dependência administrativa, podem ser públicas (federais, estaduais e municipais) ou privadas,

${ }^{1}$ No mesmo sentido, Muriel (2006, p. 47).

${ }^{2}$ Em sentido equivalente Martins (1981) e Trigueiro (2000). 
conforme art. 19 Lei no 9.394 (BRASIL, 1996), de 20 de dezembro de 1996, Lei de Diretrizes e Bases da Educação Nacional (LDB). Quando privadas, e com relação à constituição jurídica de sua mantenedora, classificam-se como fundações, associações civis ou sociedades civis de direito privado. Quanto aos fins das instituiç̧ões privadas, elas podem ser lucrativas ou não. Quanto à composição dos membros das instituições (BRASIL, 1996, art. 20), são particulares em sentido estrito, comunitárias, confessionais ou filantrópicas ${ }^{3}$. As IES são laicas quando não atendem à orientação confessional. Quanto à organização acadêmica, podem ofertar cursos, graduações e pós-graduações, possuindo ou não atividades de extensão e pesquisa. Por fim, podem levar em consideração ou não a titulação do corpo docente.

No que tange aos critérios de diferenciação supracitados, cabe ressaltar que o conceito de universidade pode ser encontrado na LDB (BRASIL, 1996), no art. 52. Assim, as universidades são instituições pluridisciplinares que formam pessoas em nivel superior, atuam em pesquisas, atividades de extensão, trabalhando o conhecimento humano, de maneira que oferecem, de forma regular, "atividades de ensino, de pesquisa e de extensão" (BRASIL, 2001, art. 80)4. Acrescenta-se que a universidade "é constituída por um conjunto de unidades (centros, institutos, faculdades, departamentos, laboratórios e núcleos). Confere graus, diplomas e títulos como os de bacharel, licenciado, especialista, mestre e doutor" (CAMPOS; MACHADO, 2000, p. 350-351).

Os centros universitários, por sua vez, são IES pluricurriculares, caracterizadas pela extrema qualidade no ensino ofertado, mediante comprovação prévia nas avaliações do Ministério da Educação (MEC), qualificação privilegiada dos docentes e pelas excelentes condições dos trabalhos acadêmicos fornecidos à sociedade. Possuem autonomia universitária para criar, organizar e extinguir cursos de ensino superior e progra-

3 Salienta-se que as IES filantrópicas são aquelas formadas por grupos que se vinculam à alguma causa humanitária.

4 Coloca-se de manifesto que o Decreto no 3.860 (BRASIL, 2001), foi revogado, parcial e totalmente, pelos Decretos $\mathrm{n}^{\circ} 4.914$ (BRASIL, 2003); 5.225 (BRASIL, 2004); 5.773 (BRASIL, 2006b); e 5.786 (BRASIL, 2006c), respectivamente. Contudo, como os posteriores atos administrativos normativos, antes mencionados, não apresentaram os elementos identificadores das universidades, faculdades integradas e estabelecimentos isolados, buscou-se no decreto antigo tais dados. Destaca-se que o Projeto de Lei de Reforma Universitária (BRASIL, 2006f), em seu art. $9^{\circ}$ dispôs que: "as instituições de ensino superior, quanto à sua organização e prerrogativas acadêmicas, podem ser classificadas como: universidades; centros universitários; ou faculdades". No mesmo projeto, o art. 12 define as condições para que as IES sejam universidades; o art. 16, os requisitos dos centros universitários e o art. 18, caput e parágrafo único, delineia as faculdades, inclusive integradas. 0 Decreto $n^{\circ} 3.860$ (BRASIL, 2001), no seu art. $8^{\circ}-$ As universidades caracterizam-se pela oferta regular de atividades de ensino, de pesquisa e de extensão, atendendo ao que dispõem os arts.52, 53 e 54 da Lei $n^{\circ} 9.394$ (BRASIL, 1996). $§ 1^{\circ}$ As atividades de ensino previstas no caput deverão contemplar, nos termos do art. 44 da Lei $\mathrm{n}^{\circ}$. 9.394, de 1996, programas de mestrado ou de doutorado em funcionamento regular e avaliados positivamente pela Coordenação de Aperfeiçoamento do Pessoal de Nivel Superior (CAPES). § 2 A criação de universidades especializadas, admitidas na forma do parágrafo único do art. 52 da Lei nº 9.394 (BRASIL, 1996), darse-á mediante a comprovação da existência de atividades de ensino e pesquisa, tanto em áreas básicas como nas aplicadas, observado o disposto neste artigo. § $3^{\circ}$ As universidades somente serão criadas por credenciamento de instituições de ensino superior já credenciadas e em funcionamento regular, com qualidade comprovada em avaliações coordenadas pelo Ministério da Educação (BRASIL, 2001). 
mas de educação de mesmo nível, estendendo ou remanejando vagas nos que já existem, desde que o façam em sua sede institucional (BRASIL, 2006c).

Os conceitos de faculdades integradas e estabelecimentos isolados podem ser extraídos do art. 12, do revogado Decreto $n^{\circ} 3.860$ (BRASIL, 2001) ${ }^{6}$, posto que as primeiras são IES com propostas de currículo em duas ou mais áreas de conhecimento, organizadas mediante regimento comum e direção central. Os estabelecimentos ou faculdades isolados, por consequência, são IES com currículo ou currículos em apenas uma área de conhecimento, possuindo direção e regimento interno exclusivos.

Destaca-se que o art. 12, do atual Decreto n 5.773 (BRASIL, 2006b), parece não ter previsto a subdivisão entre faculdades integradas e estabelecimentos isolados, quando se pensa em credenciamento e recredenciamento de IES? ${ }^{7}$. Apesar de a norma não prever expressamente, a diferenciação doutrinária deve permanecer, para respeitar a realidade social, política, econômica e regional das instituições, no momento de suas respectivas avaliações.

Apresentado o que se denomina heterogeneidade institucional, Cunha (2003) destaca a necessidade de discussão sobre a concepção de universidade, sem olvidar a pluralidade existente no Brasil. Trata-se de um alerta de extrema importância, já que o surgimento tardio das universidades brasileiras e a sua forma de constituição (associação por unidades de ensino), contribuirá para a dissolução do citado conceito de condições reais de meras faculdades.

Este artigo é preponderantemente teórico-documental, exaurindo a parte legal que trata do tema abordado, sob uma perspectiva dogmática, empregada como forma de análise dos resultados.

5 Art. $1^{\circ}$ Decreto $\mathrm{n}^{\circ} 5.786$ (BRASIL, 2006c) - Os centros universitários são instituições de ensino superior pluricurriculares, que se caracterizam pela excelência do ensino oferecido, pela qualificação do seu corpo docente e pelas condições de trabalho acadêmico oferecidas à comunidade escolar. Parágrafo único. Classificam-se como centros universitários as instituições de ensino superior que atendam aos seguintes requisitos: I - um quinto do corpo docente em regime de tempo integral; e II um terço do corpo docente, pelo menos, com titulação acadêmica de mestrado ou doutorado. Art. $2^{\circ}$ - Os centros universitários, observado o disposto no Decreto $\mathrm{n}^{\circ} .5 .773$ (BRASIL, 2006b) poderão criar organizar e extinguir, em sua sede, cursos e programas de educação superior, assim como remanejar ou ampliar vagas nos cursos existentes, nos termos deste Decreto: $\S 1^{\circ} 0$ disposto no caput deverá observar os limites definidos no plano de desenvolvimento da instituição.§ $2^{\circ}$ É vedada aos centros universitários a atuação e a criação de cursos fora de sua sede, indicada nos atos legais de credenciamento. $\S 3^{\circ}$ Os centros universitários somente serão criados por credenciamento de instituições de ensino superior já credenciadas e em funcionamento regular, com avaliação positiva pelo Sistema Nacional de Avaliação da Educação Superior (SINAES).§ $4^{\circ}$ Os centros universitários poderão registrar diplomas dos cursos por eles oferecidos.

6 Art. 12 Decreto $\mathrm{n}^{\circ} 3.860$ (BRASIL, 2001) (revogado) - Faculdades integradas são instituições com propostas curriculares em mais de uma área de conhecimento, organizadas para atuar com regimento comum e comando unificado.

7 Art. 12 Decreto $\mathrm{n}^{\circ} 5.773$ (BRASIL, 2006b) - As instituições de educação superior, de acordo com sua organização e respectivas prerrogativas acadêmicas, serão credenciadas como: I - faculdades; II centros universitários; e III - universidades (BRASIL, 2006). 


\section{Relação Jurídico-Educacional}

Portanto, devem ser analisados a natureza e o regime juridico das IES, a partir dos setores público e privado.

Ranieri (2000) ${ }^{8}$ explica que o desdobramento dos segmentos em público e privado decorre da não exclusividade no fornecimento da educação pelo Estado, e que a LDB tentou criar um nível de articulação inovador entre os setores, "a partir de uma matriz de controle final de resultados que amplia o grau de atuação autônoma das instituições" ${ }^{\text {. }}$. Assim, a educação superior caberá às IES, públicas ou particulares, com diversos níveis de "abrangência ou especialização", segundo 0 art. 45 LDB (BRASIL, 1996). Tal afirmativa acarreta dois problemas inter-relacionados, ou seja, o vínculo entre extensão, ensino e pesquisa e a apresentação do paradigma universitário como o ideal em um sistema de ensino superior heterogêneo ${ }^{10}$. Como os programas de pós-graduação stricto sensu costumam situarse nas universidades públicas, em função da pesquisa desenvolvida, o modelo a ser seguido não assegura a associação exigida pelo art. 207 CR/88 (BRASIL, 1988), demonstrando que "a fórmula idealizada pela Lei n 5.540/68, em verdade, mostrou-se irreal na grande maioria das instituições" (RANIERI, 2000, p. 184).

0 já citado art. 19 da LDB (BRASIL, 1996) classifica as IES segundo sua dependência perante outro ente mantenedor, para se empregar o regime jurídico de público ou privado. Em outro turno, as IES privadas, por força do art. 213 CR/88 (BRASIL, 1988) e da destinação das verbas públicas, classificaram-se pela composição de seus membros em particulares em sentido estrito, comunitárias, confessionais ou filantrópicas, em conformidade com o também analisado art. 20 LDB. Salienta-se "a flexibilidade de estruturas que preside essas disposições, flexibilidade que também se reflete na definição de universidade" (RANIERI, 2000, p. 18). A conceituação de universidade funde questões idealistas e funcionais, manifestadas em padrões qualitativos, ligados ao corpo docente e na indissociabilidade entre pesquisa, extensão e ensino, segundo Ranieri (2000).

Para as IES públicas, não se determinou qualquer forma amparada na administração pública indireta (BRASIL, 1988), o que Ranieri (2000) alega ser uma medida inócua, porque inexiste no sistema jurídico pátrio outra possibilidade de constituição. Dessa forma, em todos os sistemas de ensino, somente a lei, de iniciativa do Chefe do Executivo, aprovada pelo Poder Legislativo, pode instituir IES públicas, universitárias ${ }^{11}$ ou não

8 RANIERI, N. B. Educação superior, direito e estado: na Lei de Diretrizes e Bases (Lei no 9.394/96). São Paulo: EdUSP: FAPESP, 2000. 408p. Salienta-se que esse livro é o marco teórico deste estudo.

Id., Ibid., p. 183.

10 Em conformidade com o art. $2^{\circ}$ Lei $\mathrm{n}^{\circ} 5.540$ (BRASIL, 1968) "o ensino superior, indissociável da pesquisa, será ministrado em universidades e, excepcionalmente, em estabelecimentos isolados, organizados como instituições de direito público ou privado".

11 Ranieri (2000, p. 187) insere as universidades nesse contexto, independentemente da atribuição constitucional da auto-normação, segundo art. 207 da CR/88. 
(arts. 48, inciso XI, 37, inciso XIX, CR/88), mediante a forma e regime jurídico previstos para a Administração Indireta, isto é, pelo regime autárquico ou fundacional comum. Por isso, Ranieri (2000) comenta que a tardia chance de se estabelecer um modelo especial pode concretizar-se na análise de cada situação, tendo em vista o art. 54 LDB, posto que nenhuma lei ordinária pode criar estatuto jurídico diferenciado aos formulados pelo art. 37, inciso XIX, CR/88. Nesse sentido, sentencia com total pertinência:

A LDB, neste particular aspecto, normatiza com extraordinário realismo: cria condições para que a especialidade do regime aflore, em cada situação, de acordo com as finalidades e as especificidades da instituição, atendendo ao princípio da unidade da Constituição ${ }^{12}$ e à tradição jurídica brasileira de direito público, baseada na racionalidade formal do Direito Administrativo e nas formas de administração pública indireta, definidas no artigo 37, XIX, da Constituição Federal. É por esta razão que, não obstante a omissão da expressão "autarquia de regime especial" na atual LDB, os órgãos assim criados, ou qualificados, não perdem o fundamento legal de sua natureza jurídica, numa clara aplicação do princípio da continuidade da ordem jurídica (RANIERI, 2000, p. 188-189).

Além disso, Ranieri (2000) assinala a possibilidade de concessão de recursos orçamentários próprios às universidades públicas, com o objetivo de desenvolver e manter o ensino, pois não existe qualquer contradição com o antes mencionado art. 167, inciso IV, CR/88, já que outorga aplicabilidade ao art. 207 e exequibilidade ao art. 206, inciso IV (BRASIL, 1988), permitindo a autonomia universitária e a gratuidade do ensino público em estabelecimentos oficiais. Ainda há o art. 213 (BRASIL, 1988) que também permite tal destinação a instituições particulares. Com isso, a autonomia de gestão financeira é indispensável à eficiência nas universidades públicas, que possuem especificidades institucionais diferenciadas, para que se possa planejar e administrar para atingir excelentes resultados, segundo as leis específicas, que não podem, jamais, violar a CR/88 (BRASIL, 1988). Tais fundamentos deram causa à criação de fundações universitárias pelos Estados membros, para flexibilizar o regime jurídico público, com relação à administração econômica e de pessoal. Apesar de não ser objeto deste estudo, a descentralização desejada não foi obtida. Assim:

12 Cabe destacar que unidade da CR/88 determina que a interpretação constitucional deve se realizar de modo a impedir contradições entre suas próprias disposições, exigindo do hermeneuta uma análise como um "articulado de sentido" (FERRAZ JÚNIOR, 1990, p. 86), "dominado por uma lógica hierárquica que se manifesta, horizontal e verticalmente, por meio de disposições coordenadas e inter-relacionadas que se condicionam reciprocamente e em escalões sucessivos" (RANIERI, 2000, p. 72). Em sentido equivalente, "a definição material de normas constitucionais - melhor: a junção ou acrescento de uma definição material a uma definição formal - tende a esvaziar-se progressivamente de sentido. $\mathrm{Na}$ realidade, a admitir-se a distinção entre normas material e formalmente constitucionais e normas formal mas não materialmente constitucionais (para, por ex., distinguir o objecto de vários ramos do direito público) correr-se-ia o risco de dissolução da unidade normativa da constituição. Significa isto dizer que todas as normas da constituição tem o mesmo valor, daí derivando ser insustentável a tentativa de supra e infra ordenação de normas constitucionais” [...] (CANOTILHO, 1993, p. 70-71). 
Com efeito, instituir uma fundação significa afetar patrimônio a fim determinado e dar personalidade jurídica a um determinado ente que, em nome próprio, gerenciará aquele patrimônio tendo em vista os objetivos estabelecidos pelo instituidor. Quando o Estado as institui, pode atribuirIhe o regime jurídico administrativo, com todas as prerrogativas e sujeições que Ihes são próprias, ou subordiná-las ao Código Civil, com derrogações por normas de direito público. É o que permite a Lei $n^{\circ} 7.596$, de 10/4/87 que, alterando a redação do artigo $4^{\circ}$, do Decreto-lei $n^{\circ} 200$, de 25/2/67, definiu as fundações públicas, órgãos da administração indireta, como pessoas jurídicas de direito privado. Logo, em cada caso concreto, a natureza jurídica da fundação (pública ou privada) há de ser extraída do exame da lei instituidora e dos respectivos estatutos.

[...]

Do exame de algumas de suas disposições legais avulta a inadequação do modelo à gestão administrativa e financeira das fundações universitárias: não-participação direta no orçamento da União, que fica desobrigada da previsão de dotação anual para as fundações (situação hoje superada para as instituições de ensino mantidas pela União, em face do artigo 55, da LDB); participação de, pelo menos, um terço de recursos privados na constituição do patrimônio; supervisão ministerial no que respeita à execução de orçamento-programa e programação financeira, etc.

Premidas pela ausência de patrimônio próprio e pelo atendimento do princípio da gratuidade do ensino nos estabelecimentos oficiais (artigo 206, IV, da CF), as instituições são totalmente dependentes do MEC, descaracterizandose a descentralização pretendida.

Atualmente algumas fundações municipais de ensino no Estado de São Paulo, valendo-se da instituição sob regime privado e da disposição do artigo 11, V, da LDB, oferecem cursos superiores não gratuitos, sem qualquer vínculo administrativo com o poder instituidor, aí se configurando, aparentemente, uma aplicação mais adequada do modelo fundacional.

Resta saber se o seu patrimônio foi constituído mediante dotação do Município, o que fixaria a natureza pública do órgão, ainda que o legislador municipal tenha optado, em sua criação, pela atribuição de personalidade de direito privado. Em caso positivo, tratar-se-ia, desenganadamente, de fundação instituída e mantida pelo poder público e a ele vinculada, ai se apresentando outro problema de ordem constitucional e legal, voltado à não-gratuidade do ensino (artigo 206, IV) e ao atendimento do artigo 11, V, da LDB (RANIERI, 2000, 192-193). 
Por sua vez, o regime jurídico das IES particulares ${ }^{13}$ guarda, primeiramente, identidade com a natureza jurídica da entidade mantenedora ${ }^{14}$, ou seja, pessoas físicas ou jurídicas de direito privado que financiam e administram as primeiras, de acordo com o art. 19, inciso II, LDB. Do mesmo modo, o art. 20 LDB, quando classifica as IES particulares, segundo a composição dos membros de sua mantenedora, apresentando os pressupostos que devem ser cumpridos pela última. Tais elementos ensejam:

\section{[...] a preocupação da LDB com a atividade econômica na área educacional, exercida, no geral, de forma com- plementar, por dois entes distintos: uma pessoa física ou jurídica, com capacidade econômico-financeira, ti- tular do patrimônio (a mantenedora), e outra pessoa ju- rídica, prestadora de serviços, que congrega a capacida- de física instalada e os recursos humanos disponíveis (a mantida) (RANIERI, 2000, 194).}

Ainda para Ranieri (2000), a divisão entre as atividades de ensino e gestão institucional foi criada no ordenamento jurídico brasileiro pelo art. 21 Lei n 4.024 (BRASIL, 1961) $)^{15}$, abandonado, posterior e implicitamente, pelos arts. $4^{016}$ e 11 , alínea "a"17, Lei no 5.540/68.

13 De acordo com Muriel (2006, p. 68), a IES privada mantida é "instituição sem personalidade jurídica, denominada no direito como 'ente despersonalizado', que oferece ensino, pesquisa e extensão, mantida por uma entidade com personalidade jurídica (Mantenedora)".

14 Trata-se da "entidade que mantém Instituições de Ensino, sendo juridicamente responsável por esta e se relacionando com ela por intermédio de uma Diretoria ou órgão semelhante. Não interfere em questões da administração acadêmica da Instituição de Ensino, mas em questões relativas à administração financeira" (MURIEL, p. 68).

15 Art. 21 Lei $\mathrm{n}^{\circ} 4.024$ (BRASIL, 1961) - 0 ensino, em todos os graus, pode ser ministrado em escolas públicas, mantidas por fundações cujo patrimônio e dotações sejam provenientes do Poder Público, ficando o pessoal que nelas servir sujeito, exclusivamente, às leis trabalhistas (Revogado pela Lei ${ }^{\circ}$ 5.692/71). \& $1^{\circ}$ Estas escolas, quando de ensino médio ou superior, podem cobrar anuidades, ficando sempre sujeitas a prestação de contas, perante o Tribunal de Contas, e a aplicação, em melhoramentos escolares, de qualquer saldo verificado em seu balanço anual (Revogado pela Lei $\mathrm{n}^{\circ}$ 5.692/71). \& $2^{\circ} \mathrm{Em}$ caso de extinção da fundação, o seu patrimônio reverterá ao Estado (Revogado pela Lei no 5.692/71). § $3^{\circ}$ Lei especial fixará as normas da contribuição destas fundações, organização de seus conselhos diretores e demais condições a que ficam sujeitas (Revogado pela Lei $n^{\circ}$ 5.692/71) (BRASIL, 1961).

16 Art. $4^{\circ}$ Lei $\mathrm{n}^{\circ}$ 5.540/68 - As universidades e os estabelecimentos de ensino superior isolados constituirse-ão, quando oficiais, em autarquias de regime especial ou em fundaç̃es de direito público e, quando particulares, sob a forma de fundações ou associações (Revogado pela Lei no 9.394/96) (BRASIL, 1968).

17 Art. 11 Lei $\mathrm{n}^{0} 5.540$ (BRASIL, 1968) - As universidades organizar-se-ão com as seguintes características (Revogado pela Lei no 9.394/96): a) unidade de patrimônio e administração; b) estrutura orgânica com base em departamentos reunidos ou não em unidades mais amplas; c) unidade de funções de ensino e pesquisa, vedada a duplicação de meios para fins idênticos ou equivalentes; d) racionalidade de organização, com plena utilização dos recursos materiais e humanos; e) universalidade de campo, pelo cultivo das áreas fundamentais dos conhecimentos humanos, estudados em si mesmos ou em razão de ulteriores aplicações e de uma ou mais áreas técnico-profissionais; f) flexibilidade de métodos e critérios, com vistas às diferenças individuais dos alunos, às peculiaridades regionais e às possibilidades de combinação dos conhecimentos para novos cursos e programas de pesquisa (BRASIL, 1968). 
Não obstante, os arts. 19 e 20 da LDB (BRASIL, 1996) retomaram o paradigma instituído em 1961, em função dos efeitos decorrentes da dualidade entre mantenedora e mantida e a obrigatoriedade de identidade de naturezas jurídicas, entre elas, civil ou empresarial, arts. $7^{\circ}-A_{1} 7^{\circ}-B, 7^{\circ}-C$ e $7^{\circ}-$ D (BRASIL, 1995), com redação dada pela Lei ${ }^{\circ}$ 9.870 (BRASIL, 1999), ou seja, em virtude das "implicações fiscais e previdenciárias que decorrem da existência, ou não, de finalidade lucrativa nas instituições de educação" (RANIERI, 2000, p. 195), delimitando a incidência da imunidade tributária (art. 150, inciso VI, alínea "c", e seu § $4^{\circ}$ (BRASIL, 1988) e da isenção de contribuições à seguridade social (art. 195, § $7^{\circ}$ (BRASIL, 1988) ${ }^{18}$. De maneira que não há óbice legal para que sejam exercidas, em apenas uma entidade, todas as atribuições administrativas, econômicas e de ensino, relativas à atividade educacional, desde que o regime jurídico, civil ou empresarial, esteja expresso nos atos constitutivos das IES. Caso haja separação das atividades, a lei determina que a mantenedora e a mantida possuam a mesma natureza ${ }^{19}$, embora sejam pessoas jurídicas diferentes, "para que da bipartição não se" beneficie "a entidade mantenedora de uma aparente finalidade não lucrativa" (RANIERI, 2000, p. 196), mandamento cuja base legal está nos arts. 170, parágrafo único, 209, caput e inciso I (BRASIL, 1988), e 19 e 20 da LDB (BRASIL, 1996).

Como consequência, o processo de instituição e avaliação das IES, inclusive os procedimentos de credenciamento e recredenciamento, estão atrelados à finalidade lucrativa ou não das instituições, mediante definição preliminar na sua criação, conforme art. 7-B, parágrafo único, Lei no 9.131 (BRASIL, 1995), com redação dada pela Lei no 9.870/ 99. Salienta-se que a relação jurídica entre entidades mantenedoras e mantidas não é objeto deste estudo, devendo ser analisado posteriormente em outro trabalho.

Portanto, além do desejo do legislador em criar, para as universidades públicas, parâmetros jurídicos específicos (BRASIL, 1996, art. 54), diferenciados dos das demais pessoas administrativas do Estado, e com idiossincrasia autonômica (BRASIL, 1988, art. 207), leia-se:

[...] no geral, amplo é o espaço de organização acadêmica que ora se oferece às universidades. A lei não prevê os elementos de sua estrutura interna, tendo omitido qualquer menção à departamentalização, além de autorizar a criação de universidades especializadas por campo do saber ( $\$$ único, do artigo 52), opções coerentes com a autonomia universitária.

${ }_{18}$ A Lei $\mathrm{n}^{\circ} 9.732$ (BRASIL, 1998), em art. $4^{\circ}$, outorgou aplicabilidade ao referido dispositivo constitucional, nos seguintes termos: "as entidades sem fins lucrativos educacionais e as que atendam ao Sistema Único de Saúde, mas não pratiquem de forma exclusiva e gratuita atendimento a pessoas carentes, gozarão da isenção das contribuições de que tratam os arts. 22 e 23 da Lei n ${ }^{\circ} 8.212$, de 1991, na proporção do valor das vagas cedidas, integral e gratuitamente, a carentes e do valor do atendimento à saúde de caráter assistencial, desde que satisfaçam os requisitos referidos nos incisos I, II, IV e V do art. 55 da citada Lei, na forma do regulamento" (BRASIL, 1998), sem prejuízo do recolhimento da contribuição social do salário-educação, nos termos do Decreto $\mathrm{n}^{\circ}$ 3.142/99, e das Leis $\mathrm{n}^{0}$ 9.424/96 e $\mathrm{n}^{\circ} 9.766 / 98$.

19 Entenda-se identidade de naturezas jurídicas. 
A lógica da LDB, neste aspecto, estimula a criatividade organizacional (em consonância com o disposto no artigo 206, II e III, da CF), favorecendo a melhor adequação das instituições ao meio em que se inserem. Também amplia as possibilidades de adesão do sistema de ensino superior público ao Programa Nacional de Publicização, por via da qualificação de instituições privadas como "organizações sociais", na forma da Lei no 9.637, de 15/5/98 (RANIERI, 2000, p. 186).

Em continuação, o art. 45 da LDB (BRASIL, 1996) estabelece que a educação superior será fornecida em IES, "com variados graus de abrangência ou especialização". Nesse contexto, 0 art. 12 Decreto n 5.773 (BRASIL, 2006b) explicita que as IES, em função da organização e prerrogativas acadêmicas, são credenciadas como faculdades, centros universitários e universidades ${ }^{20}$.

\section{Níveis de abrangência ou especialização das IES}

Os diversos níveis de abrangência ou especialização, mencionados nos arts. 45 (BRASIL, 1996) e 12 e 13 do Decreto $n^{\circ} 5.773$ (BRASIL, 2006), envolvem a classificação das IES, segundo a natureza institucional ou administrativa e parecem formulados, segundo Ranieri (2000), em função da vinculação entre ensino e pesquisa, ou seja, sua associação ou não. Assim, o art. 52 da LDB (BRASIL, 1996) utiliza tal parâmetro para conceituar as universidades, apresentando o maior grau de abrangência e especialização do sistema educacional brasileiro, em conformidade com o art. 207, caput da CR/88 (BRASIL, 1988).

Critica-se a criação dos diferentes graus por ato administrativo normativo, como foi feito para o sistema federal pelo Decreto $n^{\circ} 2.306$ (BRASIL, 1997). Os fundamentos da critíca começam pela omissão proposital do legislador, que se limitou "a estabelecer critérios mínimos para qualificar as universidades, acompanhando os princípios educacionais da liberdade de ensino e pesquisa e do pluralismo de concepções pedagógicas" (RANIERI, 2000, p. 207), nos termos dos arts. 206, incisos II e III (BRASIL, 1988) e 3º, incisos II e III (BRASIL, 1996). Em primeiro lugar, os decretos de execução são regras jurídicas de formulação administrativa, vedando-se a integração de comando normativo originário ${ }^{21}$. Ade-

20 A origem da classificação quanto à natureza institucional ou administrativa remonta a Lei $\mathrm{n}^{\circ} 5.540$ (BRASIL, 1968), que, em seu art. $8^{\circ}$, dispõe: “os estabelecimentos isolados de ensino superior deverão, sempre que possível incorporar-se a universidades ou congregar-se com estabelecimentos isolados da mesma localidade ou de localidades próximas, constituindo, neste último caso, federações de escolas, regidas por uma administração superior e com regimento unificado que lhes permita adotar critérios comuns de organização e funcionamento" (Revogado pela Lei n ${ }^{\circ}$ 9.394/96).

21 Para Bandeira de Mello (1998), ato administrativo é declaração do Estado ou de algum concessionário de serviço público que, ao exercer suas prerrogativas públicas, apresenta medidas jurídicas assessórias da lei, somente para dar cumprimento explícito à mesma, sujeitas, ainda, ao controle jurisdicional. Em sentido equivalente, "tais atos, conquanto normalmente estabeleçam regras gerais e abstratas de conduta, não são leis em sentido formal. São leis apenas em sentido material, vale dizer, provimentos executivos com conteúdo de lei, com matéria de lei. Esses atos, por serem gerais e abstratos, têm a mesma normatividade da lei e a ela se equiparam para fins de controle judicial, mas, quando, sob a aparência de norma, individualizam situações e impõem encargos específicos a administrados, são considerados de efeitos concretos e podem ser atacados e invalidados direta e indiretamente por via judicial comum, ou por mandado de segurança, se lesivos de direito individual líquido e certo (MEIRELLES, 1997a; 1997b); de maneira semelhante Caupers (2000). 
mais e em segundo lugar, por violação aos princípios da separação dos poderes e da legalidade (arts. 2 $2^{\circ}, 5^{\circ}$, inciso II, 37, caput, e 84, inciso IV (BRASIL, 1988), tendo em vista a limitação do poder normativo ou regulamentar do Executivo para a expedição de decretos à "fiel execução" da lei (BRASIL, 1988, art. 84, inciso IV). Assim:

Na Lei no 9.394/96 não há, certamente, elementos suficientes ao reconhecimento das composturas básicas dos "diversos graus de abrangência e especialização". A só leitura da lei, em especial dos artigos 16, 19, 20 e 45, evidencia que nenhuma regra de competência foi estipulada, nem se dispôs sobre os critérios reguladores da classificação acadêmica. Há apenas um vago delineamento, estabelecido a partir do artigo 52, como já foi dito. E na Lei ${ }^{\circ} 9.131 / 95$ não há qualquer menção à matéria.

Não obstante, para o sistema federal o já citado Decreto n ${ }^{\circ}$ 2.306/97 definiu os graus de abrangência e especialização das instituições por meio de classificação que leva em conta a organização acadêmica, discriminando seis categorias: universidades; centros universitários; faculdades integradas; faculdades; institutos superiores ou escolas superiores (cf. artigo $8^{\circ}$ ).

Assim, mostra-se insuficiente invocar a competência genérica da União, de organização do sistema federal de ensino, prevista no artigo $9^{\circ}$, II, da LDB, para fundamentar a discriminação promovida pelo Decreto $n^{\circ} 2.306 / 97$, na medida em que o decreto não se limita a "organizar" as instituições do sistema federal, na acepção correta do termo. 0 que ocorre, na verdade, é a criação de formas de organização institucional por decreto, sem prévio comando legal que assim dispusesse, e, o que é pior, em direção contrária ao espírito da lei (RANIERI, 2000, p. 208-209).

Apesar de procedência da crítica de Ranieri (2000), o Poder Executivo federal continuou expedindo decretos com conteúdos similares, tais como o Decreto $n^{\circ}$ 3.860 (BRASIL, 2001), revogado, parcial e totalmente, pelos Decretos n 4.914 (BRASIL, 2003); 5.225 (BRASIL, 2004); 5.773 (BRASIL, 2006b); e 5.786 (BRASIL, 2006c), respectivamente. Todavia, tramita no Congresso Nacional projeto de lei, de iniciativa do Presidente da República, sobre a Reforma Universitária (BRASIL, 2006d), que poderá resolver a inconstitucionalidade comentada pela autora (RANIERI, 2000).

Dessa forma, os Decretos no 5.773 (BRASIL, 2006b) e 5.786 (BRASIL, 2006c) ultrapassaram os limites do art. 84, inciso IV (BRASIL, 1988), pois a norma constitucional não permite que o Poder Executivo exerça competência legislativa inaugural em consequência do âmbito do poder normativo, ressalvadas as medidas provisórias, arts. 59, inciso $V$ e 62 (BRASIL, 1988) e a expedição de decreto autônomo ou independente (art. 84, inciso VI, 
aliena "a", (BRASIL, 1988)22, que não se aplica ao caso, pois tais atos normativos derivados produzem efeitos para além da organização e funcionamento da administração federal.

Além disso, haveria ilegalidade nos Decretos no 5.773 (BRASIL, 2006b) e 5.786 (BRASIL, 2006c) por incompatibilidade dos mesmos com a LDB (BRASIL, 1996), já que a última não pleiteia a referida classificação quanto à natureza institucional, mas, em sentido oposto, "permite 'variados graus de abrangência e especialização', do que resulta ilimitada a diversidade que o sistema de ensino superior poderá comportar", e não se converte em "imposição coativa de critérios forjados pelo Poder Executivo, para coibir a liberdade de ensino e pesquisa ou inibir a livre expressão do pluralismo de concepções pedagógicas" (RANIERI, 2000, p. 210), demonstrando imposição administrativa unilateral, com indícios de usurpação legislativa. Nesse ponto, Ranieri (2000) esclarece que só seria admissivel a delegação legislativa em diretrizes e bases aos Estados membros, quando autorizada por lei complementar (BRASIL, 1988, parágrafo único, art. 22), isto é, por expressa previsão legal, colocando de manifesto que as Leis no 9.131 (BRASIL, 1995) e 9.394 (BRASIL, 1996) não permitem tal conduta.

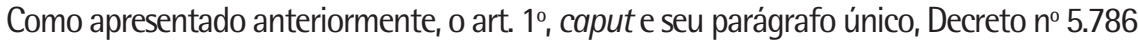
(BRASIL, 2006c) estabelece os requisitos para se classificar as IES como centros universitários. Desse modo, seriam instituições pluricurriculares, identificadas pela excelente qualidade no ensino ofertado, segundo avaliações do MEC, alta qualificação dos docentes e pelas ótimas condições dos trabalhos acadêmicos fornecidos à sociedade, repita-se. Devem cumprir, ainda, com os requisitos referentes ao corpo docente, ou seja, um quinto de seus professores com regime integral e um terço, no mínimo, com titulação de mestre ou doutor. Assim:

Como a Lei no 9.394/96 não define o que seja "excelência do ensino" (conceito tampouco sedimentado na doutrina), o seu reconhecimento, segundo critérios estabelecidos pelo MEC, permitiria a manipulação subjetiva dos parâmetros na medida em que, excluídos do processo legislativo, poderiam ser alterados a qualquer tempo, ao sabor de injunções políticas, de exigências de mercado, ou de qualquer outra razão (RANIERI, 2000, p. 210).

22 Ranieri (2000, p. 209) já previa a possibilidade de se sanar tal inconstitucionalidade em função do art. 84, inciso VI (BRASIL, 1988), se sua redação original não tratasse o decreto autônomo na forma da lei.

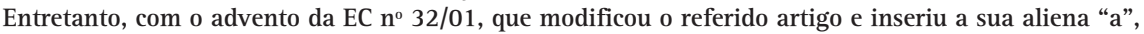
torna-se possível respaldar a constitucionalidade de tais decretos, se disserem respeito a organização e funcionamento da administração federal, o que não é o caso.

23 Art. 13 Decreto $\mathrm{n}^{\circ} 5.773$ (BRASIL, 2006b) - 0 início do funcionamento de instituição de educação superior é condicionado à edição prévia de ato de credenciamento pelo Ministério da Educação. $\$ 1^{\circ} \mathrm{A}$ instituição será credenciada originalmente como faculdade. $§ 2^{\circ} 0$ credenciamento como universidade ou centro universitário, com as consequentes prerrogativas de autonomia, depende do credenciamento específico de instituição já credenciada, em funcionamento regular e com padrão satisfatório de qualidade. $\S 3^{\circ} \mathrm{O}$ indeferimento do pedido de credenciamento como universidade ou centro universitário não impede o credenciamento subsidiário como centro universitário ou faculdade, cumpridos os requisitos previstos em lei. $\S 4^{\circ} 0$ primeiro credenciamento terá prazo máximo de três anos, para faculdades e centros universitários, e de cinco anos, para universidades. 


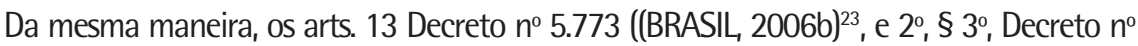
5.786 (BRASIL, 2006c) fixam que as IES somente poderão ser credenciadas, pela primeira vez, como faculdades. Ademais, as universidades ou centros universitários terão credenciamento especial, convertendo o credenciamento ordinário das faculdades em funcionamento, desde que possuam padrão de qualidade satisfatório, ante uma avaliação positiva no Sistema Nacional de Avaliação da Educação Superior (SINAES). Ranieri (2000), comentando os atos administrativos normativos da época, já apresentava críticas sobre regulamentação quase idêntica à atual, posto que é impossivel criar, de início, centros universitários (seria apenas um credenciamento como tal), o que não está expressamente previsto no art. 16, inciso II (BRASIL, 1996). Portanto, "há aqui uma limitação de direitos, tanto para a iniciativa privada quanto para o próprio poder público federal, incompatível com a ordem constitucional" (RANIERI, 2000, p. 211).

Além disso, os centros universitários estão dotados de autonomia universitária, por força dos arts. 54, $\S 2^{\circ}$ (BRASIL, 1996), e $2^{\circ}$, caput e $\S \S 1^{\circ}$ e $2^{\circ}$, Decreto $n^{\circ} 5.786$ (BRASIL, 2006c), podendo criar, organizar e extinguir cursos de ensino superior e programas de educação de mesmo nível, estendendo ou remanejando vagas nos que já existem, desde que o façam em sua sede institucional e que isso esteja expressamente previsto em seus Planos de Desenvolvimento Institucionais (PDI). Tais dispositivos possibilitam a oferta de cursos sequenciais, de graduação ou pós-graduação. Os programas de pós-graduação dos centros universitários deverão, então, empregar parcela dos recursos humanos qualificados, exigidos pelo parágrafo único, do art. $1^{\circ}$ Decreto $n^{\circ} 5.786$ (BRASIL, 2006c), da mesma forma que as universidades, no art. 52, inciso II e III (BRASIL, 1996) e sem prejuizo dos docentes com notório saber, no art. 66, parágrafo único (BRASIL, 1996), que só podem ser assim declarados pelas últimas.

Ranieri (2000) repudia as outras classificações institucionais (faculdades integradas, faculdades, institutos superiores ou escolas superiores, hoje, legalmente, apenas faculdades) posto que, pela regulamentação de então, os revogados arts. $8^{\circ}$ e 12 (BRASIL, 1997), se poderia concluir que tais IES não fornecem ensino de qualidade, o que não procede. A única diferença entre elas é o exercício da prerrogativa de autonomia, com relação à criação de cursos, programas, remanejamento ou ampliação de vagas, na educação superior. Conclui-se, então, que tais disposições ofendem os princípios educacionais constantes no art. 206, incisos II, III e VII (BRASIL, 1998), porque:

[...] a classificação de instituições no momento do credenciamento, feita não em função de graus de abrangência e especialização mas em razão da titulação e da dedicação do corpo docente, permite caracterizar essas instituições como modalidades escolares de categoria inferior em comparação às universidades, e não como modalidades dos "diversos graus de abrangência e especialização". Retoma-se desta forma, por via oblíqua, o padrão do modelo universitário, tal como vigente na Lei no $5.540 /$ 68, desvalorizando-se as instituições que dele se desviam. 
Se o intuito da regulamentação era desvincular o ensino da pesquisa e conceder autonomia a determinadas instituições, a critério do MEC ou de órgãos executivos dos sistemas de ensino - o que é legalmente possível em face dos termos da LDB (artigos 45 e 54, § $2^{\circ}$ ) - o Decreto $n^{\circ} 2.306 /$ $97^{24}$ não alcançou seu intento. Apenas favoreceu a insegurança jurídica (RANIERI, 2000, p. 212-213).

Dito isso, no sistema federal de ensino, os procedimentos referentes à avaliação e constatação das condições de funcionamento das IES e de seus cursos, bem como a definição de indicadores de qualidade e desempenho, e dos requisitos processuais a serem cumpridos, estão presentes nas Leis no 10.861 (BRASIL, 2004a) e 10.870 (BRASIL, 2004b); nos Decretos no 5.773 (BRASIL, 2006b) e 5.786 (BRASIL, 2006c); nas Portarias Normativas $n^{\circ} 1$ (BRASIL, 2007b) e 40 (BRASIL, 2007b); nas Portarias MEC no 300 (BRASIL, 2006d), 563 (BRASIL, 2006e) e 1.027 (BRASIL, 2006f); e nas Portarias n² 2.051 (BRASIL, 2004c), 107 (INEP, 2004) e 147 (BRASIL, 2007a).

\section{Conclusão}

0 Decreto n 5.773 (BRASIL, 2006b) formula a regulação das IES e dos cursos de graduação e sequenciais, no âmbito do sistema federal de ensino, estabelecendo os atos autorizativos, a partir do seu art. 9०. Tal artigo mostra-se prescindivel, já que repete integralmente o art. 209, incisos I e II (BRASIL, 1988), apresentando a liberdade do segmento particular em atuar na educação superior, desde que cumpra com as normas gerais da educação brasileira e inicie suas atividades mediante autorização e avaliação pelo Poder Público, art. $9^{\circ}$ do Decreto nº 5.773 (BRASIL, 2006b).

Com isso, o art. 10, caput e $\S \S$, Decreto $n^{\circ} 5.773$ (BRASIL, 2006b), determina que 0 ato autorizativo do Poder Público é indispensável ao funcionamento de qualquer IES e ao oferecimento de curso de nível superior.

Todavia, constatou-se a inconstitucionalidade nos atos administrativos normativos, expedidos pela Presidência da República, no tópico relativo aos diversos níveis de abrangência ou especialização das IES, especialmente nas denominações de centros universitários e faculdades (outorgadas pelos citados atos autorizativos), mencionadas nos arts. 12, incisos II e III, e 13 , §§ $1^{\circ}$ e $2^{\circ}$ do Decreto $n^{\circ} 5.773$ (BRASIL, 2006b) e no Decreto $n^{\circ} 5.786$ (BRASIL, 2006c). A discriminação formulada pelos referidos decretos não se limita a organizar as IES do sistema federal de ensino, posto que cria formas de organização institucional, sem disposição legal anterior e em sentido oposto ao do art. 45 da LDB (BRASIL, 1996).

${ }^{24}$ Entendam-se os Decretos n 5.773 (BRASIL, 2006b) e 5.786 (BRASIL, 2006c), que mantiveram dispositivos quase idênticos aos dos antigos e revogados Decretos n ${ }^{\circ} 2.306$ (BRASIL, 1997), 3.860 (BRASIL, 2001), 4.914 (BRASIL, 2003) e 5.225 (BRASIL, 2004). 
Fundamenta-se tal conclusão pela omissão proposital do legislador, que somente estabeleceu critérios mínimos para a qualificação de universidades, em virtude da liberdade de concepções pedagógicas, de ensino e pesquisa, arts. 206, incisos II e III (Brasil, 1988) e $3^{\circ}$, incisos II e III (BRASIL, 1996), sem prejuizo da violação da separação dos poderes e do abuso de poder regulamentar, conforme arts. $2^{\circ}, 5^{\circ}$, inciso II, 37, caput, e 84, incisos IV, (BRASIL, 1988).

Por fim, o Projeto de Lei de Reforma Universitária apresenta, em seu texto, elementos identificadores da tipologia das IES, formulando critérios, requisitos, condições e prerrogativas para as universidades, centros universitários e faculdades, integradas e isoladas, de acordo com o enquadramento legal e os privilégios estatuídos pelo ordenamento jurídico. Desse modo, é um excelente momento para se regularizarem as inconstitucionalidades apontadas por este estudo. É público e notório que o referido projeto é um exemplo de discussão e participação efetiva da sociedade na Administração Pública, o que respalda o Estado Democrático de Direito, no qual o Estado se submete ao exercício do dever de respeitar os cidadãos, na titularidade de seus direitos individuais e coletivos, onde todos os atos estatais devem ser controlados e fiscalizados, pois o poder emana do povo e em seu nome é exercido, demonstrando, ainda, a prevalência do ordenamento jurídico posto.

\section{Referências}

BANDEIRA DE MELLO, C. A. Curso de direito administrativo. 10. ed. São Paulo: Malheiros Editores, 1998.

BRASIL. Congresso Nacional. Senado Federal. Projeto de Lei n. 7.200, de 12 de junho 2006. Estabelece normas gerais da educação superior. Projetos, Brasília, DF, 2006a. Disponivel em: http://www.planalto.gov.br/ccivil_03/Projetos/PL/2006/ msg449-060608.htm. Acesso em: 19 de jun. 2010.

. Constituição (1988). Constituição da República Federativa do Brasil. Brasília, DF: Senado Federal, 1988.

Decreto no 2.306, de 19 ago. 1997. Regulamenta, para o Sistema Federal de Ensino, as disposições contidas no art. 10 da Medida Provisória n ${ }^{\circ}$.477-39, de 08 de agosto de 1997, e nos arts. 16, 19, 20, 45, 46 e $\S 1^{\circ}$, 52, parágrafo único, 54 e 88 da Lei no 9.394, de 20 de dezembro de 1996, e dá outras providências. Diário Oficial [da] República Federativa do Brasil, Brasília, 20 ago. 1997.

Decreto no 3.860, de 9 de julho de 2001. Dispõe sobre a organização do ensino superior, a avaliação de cursos e instituições, e dá outras providências. Diário Oficial da União, Brasilia, DF, 10 jul. 2001. 
BRASIL. Decreto n 4.914, de 11 dez. 2003. Dispõe sobre os centros universitários de que trata 0 art. 11 do Decreto $n^{\circ} 3.860$, de 09 de julho de 2001, e dá outras providências. Diário Oficial da União, Brasilia, DF, 12 dez. 2003.

Decreto $n^{\circ} 5.225$, de 1 de outubro de 2004. Altera dispositivos do Decreto $n^{\circ}$ 3.860, de 09 de julho de 2001, que dispõe sobre a organização do ensino superior e a avaliação de cursos e instituições, e dá outras providências. Diário Oficial da União, Brasilia, DF, 4 out. 2004.

. Decreto $n^{\circ} 5.773$, de 9 maio de 2006. Dispõe sobre o exercício das funções de regulação, supervisão e avaliação de instituições de educação superior e cursos superiores de graduação e sequenciais no sistema federal de ensino. Diário Oficial da União, Brasília, DF, 10 maio 2006b.

Decreto $n^{\circ}$ 5.786, de 24 de maio de 2006. Dispõe sobre os centros universitários e dá outras providências. Diário Oficial da União, Brasilia, DF, 25 maio 2006c.

. Lei no 4.024, de 20 dez. 1961. Fixa as Diretrizes e Bases da Educação Nacional. Diário Oficial [da] República Federativa do Brasil, Brasilia, DF, 27 dez. 1961.

. Lei no 5.540, de 28 nov. 1968. Fixa normas de organização e funcionamento do ensino superior e sua articulação com a escola média, e dá outras providências. Diário Oficial [da] República Federativa do Brasil, Brasília, DF, 23 nov. 1968. Retificada em 3 dez. 1968.

. Lei $n^{\circ} 9.131$, de 24 nov. 1995. Altera dispositivos da Lei $n^{\circ} 4.024$, de 20 dez. 1961, e dá outras providências. Diário Oficial [da] República Federativa do Brasil, Brasilia, DF, 25 nov. 1995.

. Lei no 9.394, de 20 dez. 1996. Lei de Diretrizes e Bases da Educação Nacional. Diário Oficial [da] República Federativa do Brasil, Brasília, DF, 23 dez. 1996.

. Lei $n^{\circ} 9.732$, de 11 dez. 1998. Altera dispositivos das Leis no 8.212 e 8.213, ambas de 24 de julho de 1991, da Lei no 9.317, de 05 de dezembro de 1996, e dá outras providências Diário Oficial [da] República Federativa do Brasil, Brasilia, DF, 14 dez. 1998.

Lei $n^{\circ}$. Lei $n^{\circ} 9.870$, de 23 nov. de 1999. Dispõe sobre o valor total das anuidades escolares e dá outras providências. Diário Oficial [da] República Federativa do Brasil, Brasília, DF, 24 nov. 1999. 
BRASIL. Lei no 10.861, de 14 abril de 2004. Institui o Sistema Nacional de Avaliação da Educação Superior - SINAES - e dá outras providências. Diário Oficial da Uniõo, Brasília, DF, 15 abr. 2004a.

Lei $n^{\circ} 10.870$, de 19 de maio de 2004. Institui a Taxa de Avaliação in loco das instituições de educação superior e dos cursos de graduação e dá outras providências. Diário Oficial da União, Brasília, DF, 20 maio 2004b.

. Ministério da Educação. Portaria nº. 147, de 2 de fevereiro de 2007. Portarias, Brasilia, DF, 2007a. Disponivel em: <http://portal.mec.gov.br/sesu/ arquivos/pdf/portarias/portaria147.pdf> . Acesso em: 28 out. 2010.

Portaria nº. 300, de 30 de janeiro de 2006. Diário Oficial da União, Brasilia, DF, n. 22, 31 jan. 2006d. Seção 1, p. 5-7.

Portaria no. 563, de 21 de fevereiro de 2006. Diário Oficial da União, Brasilia, DF, n. 38, 22 fev. 2006e. Seção 1, p. 6.

Portaria n. 1.027, de 15 de maio de 2006. Diário Oficial da União, Brasília, DF, n. 92, 15 maio 2006f. Seção 1, p. 9.

Portaria $n^{\circ}$. 2.051, de 9 de julho de 2004. Diário Oficial da União, Brasilia, DF, n. 132, 12 jul. 2004c. Seção 1, p. 12.

. Portaria Normativa $n^{0} .1$, de 10 de janeiro de 2007. Diário Oficial da União, Brasilia, DF, 11 jan. 2007b. Seção 1, p. 7.

Ministério da Educação. Portaria Normativa nº. 40, de 12 de dezembro de 2007. Diário Oficial da União, Brasília, DF, 13 dez. 2007b. Seção 1, p. 39.

Ministério da Educação. Ministério da Fazenda. Ministério da Previdência e Assistência Social. Ministério da Ciência e Tecnologia. Projeto de Lei de Reforma Universitária. In: . E. M. I. $n^{\circ}$.015/MEC/MF/MP/MCT. Brasília, DF, $2006 f$. Disponivel em: <http://www.sintufsc.ufsc.br/noticias_2006/0619_reforma.pdf>. Acesso em: 29 jan. 2008.

CAMPOS, R.; MACHADO, L. Universidade. In: FIDALGO, F.; MACHADO, L. (Ed.). Dicionário da educação profissional. Belo Horizonte: Núcleo de Estudos sobre Trabalho e Educação, 2000. Voz, p. 350-351.

CANOTILHO, J. J. G. Direito constitucional. 6. ed. Coimbra, PT: Edições Almedina, 1993. 
CAUPERS, J. Introdução ao direito administrativo. 5. ed. Lisboa, PT: Âncora Ed., 2000.

CUNHA, L. A. Ensino superior e universidade no Brasil. In: LOPES, E. M. T.; FARIA FILHO, L. M.; VEIGA, C. G. (Org.). 500 anos de educação no Brasil. 3. ed. Belo Horizonte: Autêntica, 2003.

FERRAZ JÚNIOR, T. S.. Interpretação e estudos da Constituição de 1988: aplicabilidade; congelamento, coisa julgada fiscal, capacidade contributiva, ICMS, empresa brasileira, poder constituinte estadual, medidas provisórias, justiça e segurança, servidor público. São Paulo: Atlas, 1990.

INEP. Portaria n. 107, de 22 de julho de 2004. Legis/ação, Brasilia, DF, 2004. Disponivel em: <http://portal.mec.gov.br/setec/arquivos/pdf_legislacao/rede/ legisla_rede_port107.pdf>. Acesso em: 28 out. 2010.

MARTINS, C. B. C. Ensino pago: um retrato sem retoques. São Paulo: Global, 1981. . 0 ensino superior privado no Distrito Federal. Cadernos de Pesquisa, São Paulo, n. 102, p. 157-187, nov. 1997.

MEIRELLES, H. L. Direito administrativo brasileiro. 22. ed. São Paulo: Malheiros Editores, 1997a.

. Mandado de segurança: ação popular, ação civil pública, mandado de injunção, "habeas data". 18. ed. São Paulo: Malheiros Editores, $1997 b$.

MINTO, L. W. As reformas do ensino superior no Brasil: o público e o privado em questão. Campinas, SP: Autores Associados, 2006.

MURIEL, R. Plano de Desenvolvimento Institucional (PDI): análise do processo de implantação. Vitória, ES: Ed. Hoper, 2006.

RANIERI, N. B. Educação superior, direito e estado: na Lei de Diretrizes e Bases (Lei no 9.394/96). São Paulo: EdUSP: FAPESP, 2000.

RIBEIR0, M. G. M. Educação superior brasileira: reforma e diversificação institucional. Bragança Paulista, SP: EDUSF, 2002.

SAMPAIO, H. Ensino superior no Brasil: o setor privado. São Paulo: Hucitec: FAPESP, 2000. 
SOUSA, J. V. O Ensino superior privado no Distrito Federal: uma análise de sua recente expansão (1995-2001). 2003. 279 f. Tese (Doutorado em Sociologia) Universidade de Brasilia.

TRAMONTIN, R.; BRAGA, R. 0 ensino superior particular no Brasil: traços de um perfil. In: MENDES, C.; CASTRO, C. M. (Org.). Qualidade, expansão e financiamento do ensino superior privado. Rio de Janeiro: EDUCAM; ABM, 1984. Cap. 1, p. 19-50.

TRIGUEIRO, M. G. S. Ensino superior privado no Brasil. Brasília, DF: Paralelo 15; São Paulo: Marco Zero, 2000.

Recebido em: 14/04/2009

Aceito para publicação em: 21/05/2009 